\title{
Specificity of rheumatoid factors in relation to the disease state in rheumatoid arthritis
}

\author{
M G Jones, M E Shipley, J P Hearn, F C Hay
}

\begin{abstract}
Rheumatoid factors found in patients with rheumatoid arthritis react with human IgG and with IgG from some other species. The levels of rheumatoid factor give some indication of prognosis, albeit a rather poor one in this highly variable disease. The high degree of variability may, in part, be due to differences in the fine specificity of the rheumatoid factor in each individual patient, leading to differences in the types of immune complex formed. To study this hypothesis the fine specificity of rheumatoid factors of the IgM, IgA, and IgG classes for IgG from human, baboon, orangutan, macaque, owl monkey, gorilla, marmoset, cow, pig, sheep, goat, horse, mouse, and chicken was examined. Differential reactivity for these species was found and associations between the presence of rheumatoid factor and the development of moderate or severe erosions.
\end{abstract}

Rheumatoid factors bind to normal human IgG and IgG from many different species. ${ }^{1}$ It is long established that raised levels of such antiglobulins are associated with rheumatoid arthritis and that this antiglobulin activity is found in $\operatorname{IgM}, \operatorname{IgA}$, and $\operatorname{IgG}$ classes. ${ }^{2}$ The degree of binding of rheumatoid factor to IgG of different species is controversial, as is the clinical significance of the spectrum of such polyspecific rheumatoid factor activity. Some have shown that rheumatoid factors binding with rabbit IgG are more specific for rheumatoid arthritis than are those reactive with human IgG. ${ }^{34}$ In contrast, others suggest that human rather than rabbit IgG is a better discriminator between patients with rheumatoid arthritis and controls. ${ }^{5}$ It has been shown that rheumatoid factor binding to human IgG has similar binding activity with the primate rhesus monkey IgG, but lower binding with non-primate rabbit,

The aim of this study was to examine the fine specificity of rheumatoid factors in each of the three main classes, $\operatorname{Ig} M, \operatorname{IgA}$, and $\operatorname{IgG}$, and to compare these results with various measures of disease process and outcome (particularly degree of erosiveness and presence of extra-articular manifestations) to see if any can be linked to a particular isotype or specificity of rheumatoid factor. The specificities were measured with a panel of IgGs from a variety of primate and nonprimate species and their relation to disease activity at the time of drawing the blood was established. To discover whether the pattern of reactivity with the panel of IgGs had any predictive value stored sera from patients with rheumatoid arthritis were studied and the results compared with their outcome at long term follow up.

\section{Materials and methods}

IgG PREPARATION

IgG from various species was purified by passing the serum over a DEAE-cellulose column and eluting with a gradient of increasing molarity of $0.017 \mathrm{M}$ to $0.5 \mathrm{M}$ phosphate buffer $\mathrm{pH} 8.0$.

SOLID PHASE RADIOIMMUNOASSAY

Ninety six well, flexible plates were coated with $100 \mu \mathrm{l}$ of a $10 \mu \mathrm{g} / \mathrm{ml}$ protein solution in phosphate buffered saline (PBS) $\mathrm{pH} 7 \cdot 2$ and incubated for one hour at $37^{\circ} \mathrm{C}$ and overnight at $4^{\circ} \mathrm{C}$. Unbound proteins were removed by three washes with cold PBS.

Serum $(1 \mu \mathrm{l})$ was added to each well with 100 $\mu \mathrm{l} 0.05 \mathrm{M}$ TRIS $\mathrm{HCl} \mathrm{pH} 8.0$ containing $0.05 \%$ Tween 20 (TRIS $\mathrm{HCl}$ Tween), and incubated for one hour at $37^{\circ} \mathrm{C}$ (serum dilution 1:100). The plates were then washed three times with cold TRIS HCl Tween.

Depending on the class of rheumatoid factor being detected, $100 \mu \mathrm{l}$ of $5 \mu \mathrm{g} / \mathrm{ml}$ rabbit antihuman IgM, IgA, or Fd of IgG in TRIS $\mathrm{HCl}$ Tween were added and incubated for one hour at $37^{\circ} \mathrm{C}$. The plates were then washed three times with cold TRIS $\mathrm{HCl}$ Tween. A final layer of $1 \mu \mathrm{g}{ }^{125}$ I labelled goat antirabbit IgG was added in $100 \mu \mathrm{l}$ TRIS $\mathrm{HCl}$ Tween and incubated for one hour at $37^{\circ} \mathrm{C}$. The plates were washed three times with cold TRIS HCl Tween and counted in a gammacounter.

SOLID PHASE CAPTURE ASSAY

Ninety six well, flexible plates were coated with $100 \mu \mathrm{l}$ of a $10 \mu \mathrm{g} / \mathrm{ml}$ protein solution in PBS and incubated for one hour at $37^{\circ} \mathrm{C}$ and overnight at $4^{\circ} \mathrm{C}$. Unbound proteins were removed with three washes of cold PBS.

Serum $(1 \mu \mathrm{l})$ was added to each well with 100 $\mu l$ TRIS $\mathrm{HCl}$ Tween and incubated for one hour at $37^{\circ} \mathrm{C}$ (serum dilution $1: 100$ ). The plates were then washed three times with cold TRIS $\mathrm{HCl}$ Tween.

One hundred microlitres of $5 \mu \mathrm{g} / \mathrm{ml}{ }^{125} \mathrm{I}$ aggregated IgG was added in TRIS $\mathrm{HCl}$ Tween and incubated for four hours at $37^{\circ} \mathrm{C}$. The plates were washed three times with cold TRIS $\mathrm{HCl}$ Tween and counted in a gammacounter. horse, sheep, and cow. ${ }^{6}$

Immunology Department,
St George's Hospital
Medical School,
Cranmer Terrace,
Tooting, London
SW17 ORE
M G Jones
F C Hay
Departments of
Immunology and
Rheumatology Research,
University College and
Middlesex School of
Medicine, Arthur Stanley
House, 40-50 Tottenham
Street, London W1P 9PG
M E Shipley
MRC/AFRC
Comparative Physiology
Research Group,
Institute of Zoology,
Regent's Park,
London NW1 4RY
Correspondence to:
Dr Jones.
Accepted for publication
20 November 1989


SOLID PHASE COMPETITIVE CAPTURE ASSAY

Ninety six well, flexible plates were coated with $100 \mu \mathrm{l}$ of a $10 \mu \mathrm{g} / \mathrm{ml}$ protein solution in PBS and incubated for one hour at $37^{\circ} \mathrm{C}$ and overnight at $4^{\circ} \mathrm{C}$. Unbound proteins were removed by three washes with cold PBS.

Serum $(1 \mu \mathrm{l})$ was added to the coated plates with $100 \mu$ l TRIS $\mathrm{HCl}$ Tween and incubated for one hour at $37^{\circ} \mathrm{C}$ (serum dilution 1:100). The plates were then washed three times with cold TRIS HCl Tween.

One hundred microlitres of $5 \mu \mathrm{g} / \mathrm{ml}{ }^{125} \mathrm{I}$ and unlabelled aggregated human IgG was added in TRIS $\mathrm{HCl}$ Tween and incubated for four hours at $37^{\circ} \mathrm{C}$. The plates were washed three times with cold TRIS $\mathrm{HCl}$ Tween and counted in a gammacounter.

\section{AGGREGATION OF IMMUNOGLOBULINS}

Proteins at a concentration of $27 \mathrm{mg} / \mathrm{ml}$ optimally were incubated at $63^{\circ} \mathrm{C}$ for 30 minutes and then placed on ice. The degree of aggregation was then checked by gel filtration on a Sephacryl S300 column.

\section{PATIENT SELECTION}

The patients were part of a prospective study established at the Middlesex Hospital in $1966 .^{7}$ Each patient entered the study within one year of onset of polyarthritis satisfying the criteria for at least possible rheumatoid arthritis (American Rheumatism Association criteria), other causes of inflammatory polyarthritis having been excluded. The patients attend a special research clinic about three times a year for clinical, radiological, and serological examination. The serum samples under test were taken within a year of the patient entering the study and have been stored deep frozen at $-20^{\circ} \mathrm{C}$ since then. The degree of erosion in hand and feet radiographs was assessed by a modification of the method of Lawrence ${ }^{8}$ at a minimum of 10 years' follow up.

\section{STATISTICAL METHODS}

Friedman's test was used to test for significant patterns in the antiglobulin results. ${ }^{910}$ The significance of differences in the means of antiglobulins binding to different species was determined by an analysis of variance: Duncan's multiple comparison test. ${ }^{9}$ To examine which variables were capable of discriminating between patients with erosive disease and those with a milder course, multivariant analysis using discriminant functions was performed using the statistical package for the social sciences (SPSS), version $M$, release $9 \cdot 0 .^{11}$

\section{Results}

IgM ANTIGLOBULINS

IgM antiglobulin levels were determined against the whole panel of species and were detectable against most species of IgG, though binding was considerably lower to mouse IgG and hardly detectable to chicken IgG (fig 1).

The binding to various species of IgG was

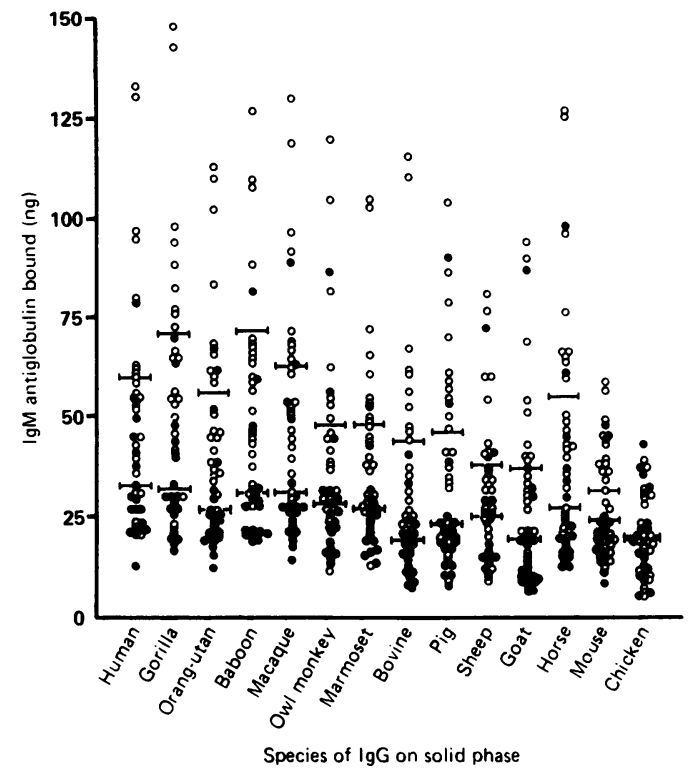

Figure 1 Binding of IgM rheumatoid factors from patients with non-erosive $(O)$ or erosive $(O)$ rheumatoid arthritis to IgG from various species presented on a solid phase.

analysed by Duncan's analysis of variance. Levels of IgM antiglobulin binding to all the mammalian species of IgG were significantly higher than that to chicken IgG (table 1). The highest binding was to human IgG and to three closely related primates: baboon, macaque, and gorilla. The binding to owl monkey and marmoset was not significantly different from that to human IgG. In addition to the low binding to chicken IgG, three other species were poor binders of rheumatoid factor: mouse, goat, and sheep, giving significantly less binding than horse, orang-utan, human, baboon, macaque, and gorilla. In between these extremes other

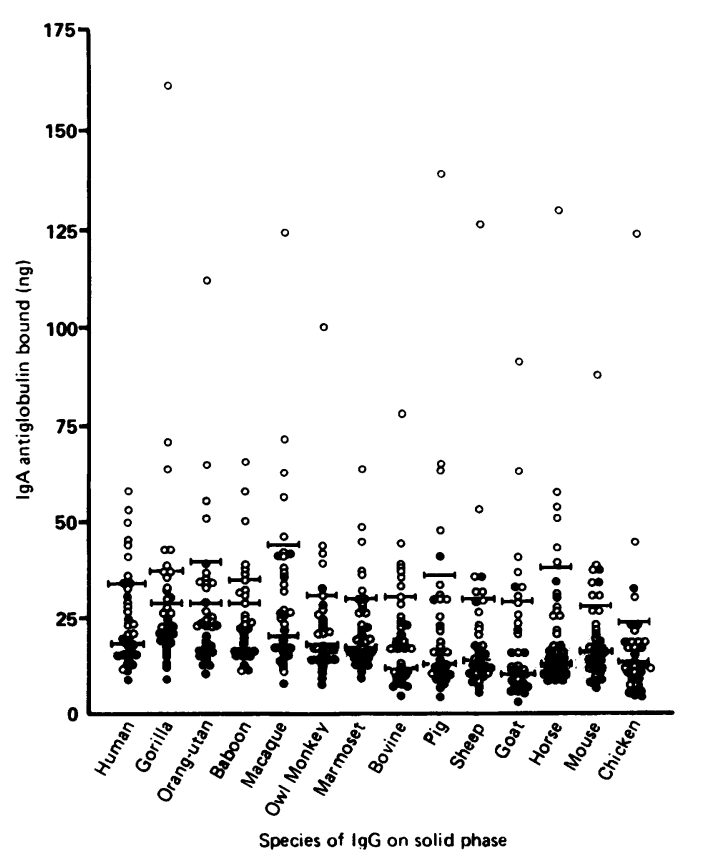

Figure 2 Binding of IgA rheumatoid factors from patients with non-erosive $(O)$ or erosive $(O)$ rheumatoid arthritis to IgG from various species presented on a solid phase. 
Table I Duncan's analysis of variance for significant differences between means for IgM antiglobulins reacting with various species of IgG

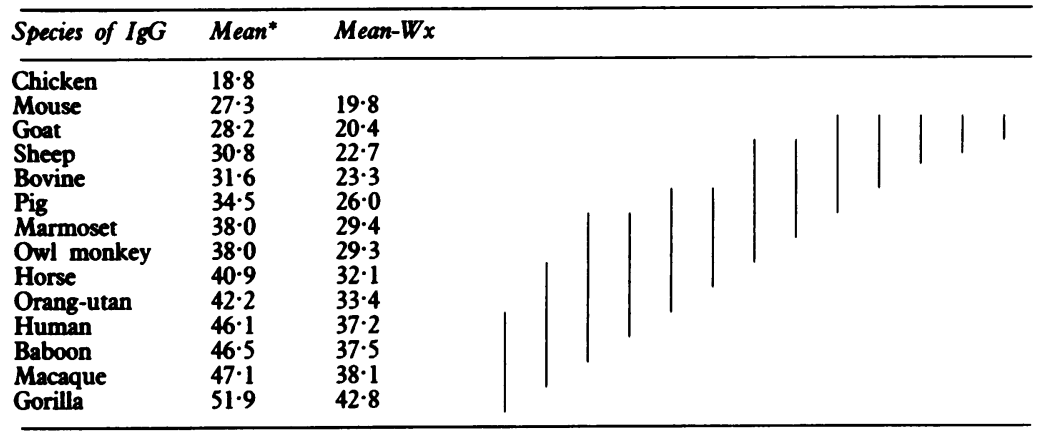

* Mean ng anti-IgM bound.

Bars link groups of means which do not differ significantly from each other.

Table 2 Duncan's analysis of variance for significant differences between means for IgA antiglobulins reacting with various species of IgG

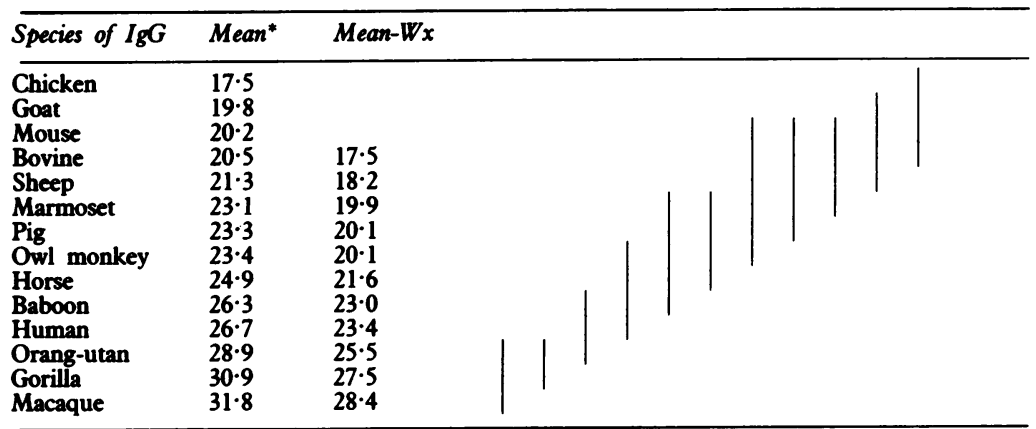

* Mean ng anti-IgA bound.

Bars link groups of means which do not differ significantly from each other.

Table 3 Duncan's analysis of variance for significant differences between means for IgG antiglobulins reacting with various species of IgG

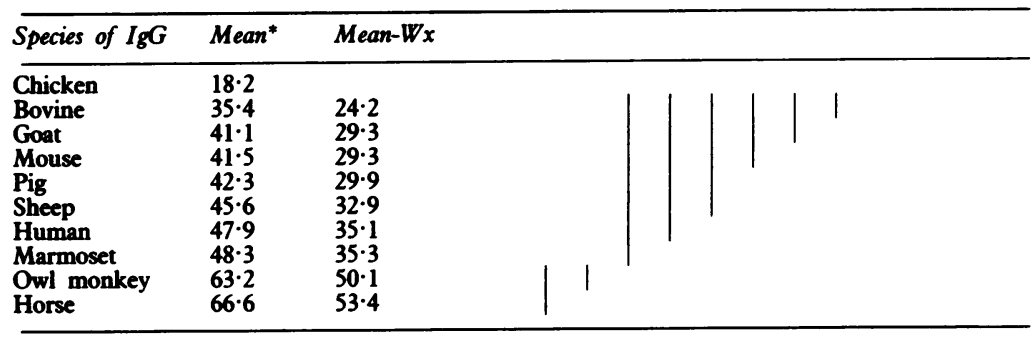

* Mean ng anti-IgG bound.

Bars link groups of means which do not differ significantly from each other.

groups of binding can be distinguished in table 1 , where any groups of specificities connected by a vertical bar do not differ significantly from each other.

IgA ANTIGLOBULINS

IgA antiglobulin levels were also determined against the panel of immunoglobulins and were detectable against most, albeit at lower levels than those for IgM antiglobulins. The binding to chicken was again the lowest of all the species, though a few individual chickens had raised levels (fig 2).

As with IgM antiglobulins, chicken, goat, mouse, and bovine IgG gave significantly lower binding (table 2). Primate IgGs were again the best antigens for IgA rheumatoid factor binding-baboon, human, orang-utan, gorilla, and macaque giving the highest reactivity. IgA antiowl monkey and horse IgG levels were not significantly different from those to human IgG.
IgG ANTIGLOBULINS

IgG antiglobulins could not be determined against the full range of species as the IgG from the Old World monkeys and apes were so similar antigenically that the anti-Fd gamma reagent used for detecting the antiglobulins reacted with whole IgG from these species; there was unfortunately insufficient serum, and thus IgG, available from these species to permit the preparation of $\mathrm{Fc}$ and thus avoid this problem. IgG antiglobulins were raised against most of the remaining species, with the exception of chicken (fig 3), which was a significantly poorer binder than any other species of IgG tested.

Binding to horse and owl monkey IgG was markedly higher than to the rest of the IgGs tested. All the remaining species, with the exception of chicken IgG, were not significantly different from each other (table 3 ).

\section{PATTERNS OF REACTIVITY WITH THE}

SPECIES OF IgG

It was possible that $(a)$ certain patients might bind strongly to some species of IgG while binding weakly to others, and that these patterns of reactivity might relate to the clinical course of the disease or that $(b)$ patients with high levels of antiglobulin to one species of IgG would be high for the whole panel.

To test these two hypotheses we used Friedman's test. The analysis was carried out in two directions. When the patient's antiglobulin levels to each species of IgG were ranked a significant trend was found $(p<0.001)$, indicating a similar pattern of antiglobulin binding to the whole panel of species of IgG. Similarly, when the antiglobulins binding with the various species were ranked to individual patients a significant trend was again found $(\mathrm{p}<0.001)$, indicating that the pattern of antiglobulin binding with the panel of species of IgG was similar with each patient. This held true for each immunoglobulin class of antiglobulin.

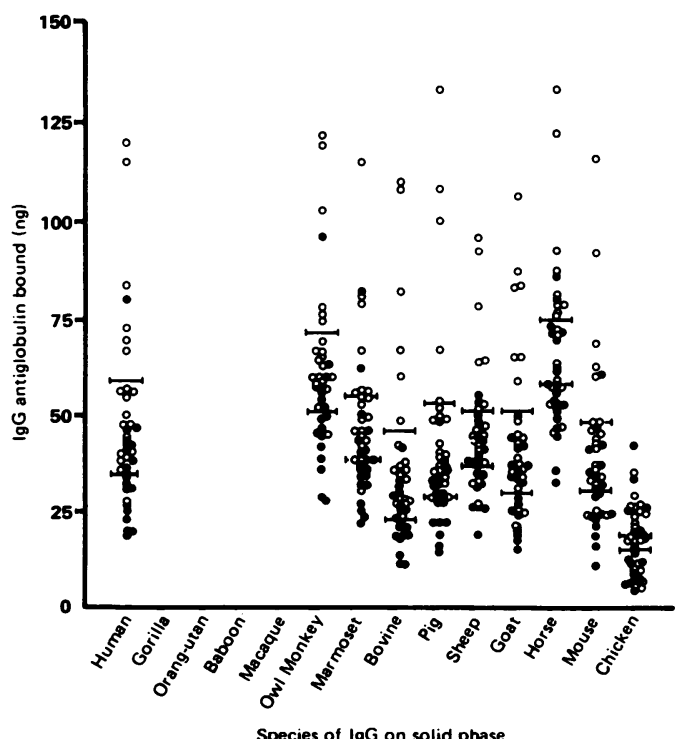

Figure 3 Binding of IgG rheumatoid factors from patients with non-erosive $(O)$ or erosive $(\mathrm{O})$ rheumatoid arthritis to IgG from various species presented on a solid phase. 
SOLID PHASE CAPTURE ASSAY

It was possible that some of the patterns of reactivity obtained might be related to the system used for measurement. Therefore we used a second experimental system, which we hoped might show increased powers of discrimination. A solid phase capture assay was set up in which rheumatoid factor bound to IgG on

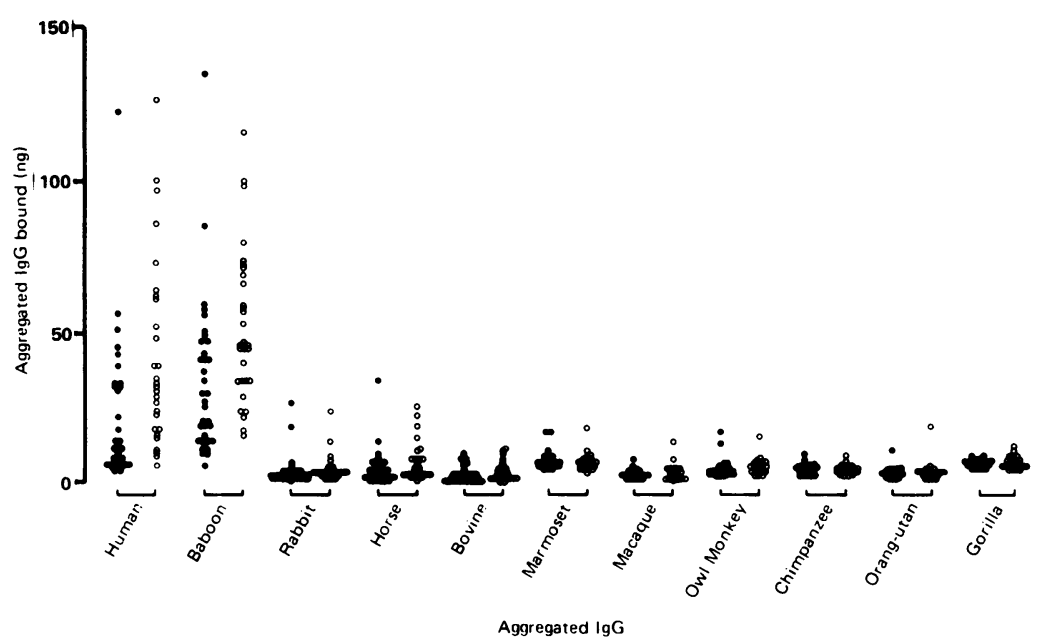

Figure 4 Capture of aggregated ${ }^{125}$ I labelled IgG from a range of species by rheumatoid factors bound to solid phase human IgG.

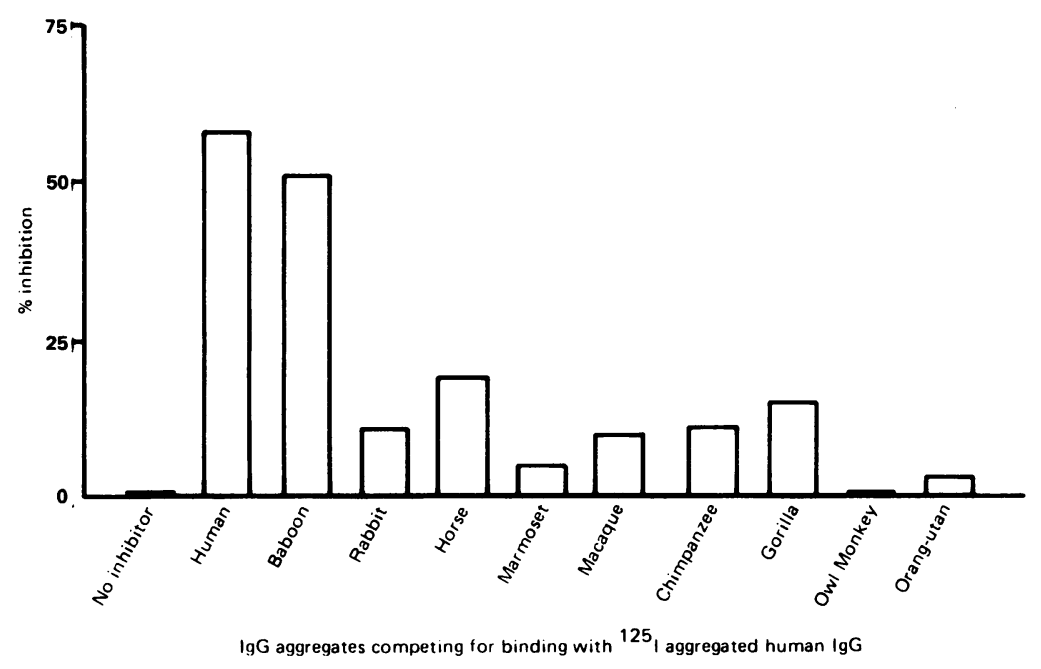

Figure 5 Competition for binding between aggregated IgG from various animal species with ${ }_{22}$ I labelled aggregated human IgG.

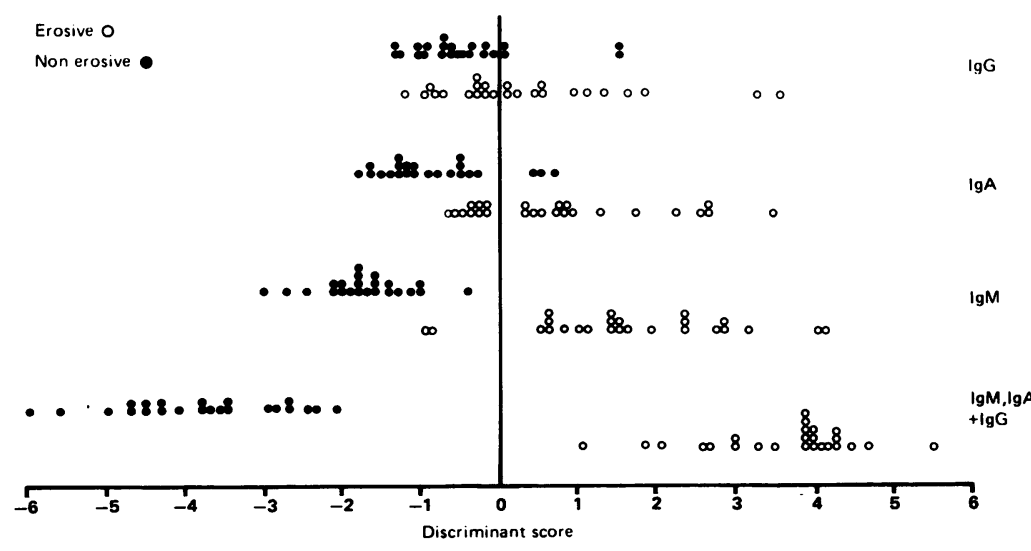

Figure 6 Discrimination between patients with erosive arthritis and those with a less erosive course of disease using multivariant analysis of rheumatoid factor binding. The degree of discrimination obtained with each immunoglobulin isotype alone and with pooled data is shown. a solid phase by at least one of its combining sites was then allowed to bind soluble phase labelled IgG of various species by its remaining antigen combining sites. The affinity of the rheumatoid factor was found to be too low to bind monomeric IgG in the soluble phase, but mildly heat aggregated human IgG was bound well by the rheumatoid factors. The assay was found to depend largely on IgM rheumatoid factor as reduction with dithiothreitol abolished the binding. All preparations of species of IgG were found to be similarly aggregated by heat as identical profiles were obtained when the aggregates were run through a Sephacryl S300 gel filtration column.

Using this assay with human IgG on the solid phase, we found that the rheumatoid factors could only bind human and baboon IgG from the soluble phase, with no binding of IgG prepared from rabbit, horse, marmoset, bovine, macaque, chimpanzee, gorilla, owl monkey, or orang-utan (fig 4). The pattern of binding was completely dependent on the soluble phase IgG used and independent of the solid phase immunoglobulin as identical patterns of solely binding human and baboon IgG were obtained when baboon, rabbit, horse, or bovine IgG were substituted for human IgG on the solid phase. This is in striking contrast with the results obtained from the solid phase radioimmunoassay (fig 1).

\section{INHIBITION OF BINDING OF LABELLED} IMMUNOGLOBULINS

To ensure that the lack of binding of certain of the species in the soluble phase was not due to damage during the radiolabelling unlabelled immunoglobulins were used to inhibit the binding of labelled aggregated human IgG. Unlabelled, mildly aggregated, human and baboon IgG were able to inhibit the binding of labelled aggregated human IgG, whereas aggregated rabbit, horse, marmoset, macaque, chimpanzee, gorilla, owl monkey, and orangutan were unable to inhibit this binding of labelled aggregated IgG (fig 5).

DISCRIMINANT ANALYSIS OF PATIENTS WITH AND WITHOUT EROSIONS

The IgM, IgA, and IgG antiglobulin levels binding with the panel of IgGs from various species were analysed by discriminant function analysis. This resulted in a $100 \%$ discrimination on the basis of the first serum sample for the prediction of whether the patient would become severely or only mildly erosive or non-erosive at later follow up. Individually the IgM isotype was better than IgA, which was better than IgG for discriminating between the erosive and nonerosive patients (fig 6).

The discriminant function derived from this analysis of $\operatorname{IgM}, \operatorname{IgA}$, and $\operatorname{IgG}$ antiglobulins was applied to the antiglobulin results obtained from a second group of $\mathbf{4 0}$ patients in an attempt to predict the degree of erosiveness that would develop at later follow up. The ability to predict in this group was only $65 \%$ accurate. 
Discussion

Rheumatoid factors of $\operatorname{IgA}, \operatorname{IgG}$, and $\operatorname{IgM}$ classes have been detected in many of the serum samples studied. These antiglobulins bound to IgG of all the species tested, albeit at varying levels. IgG on a solid phase provides a very attractive way of presenting the antigen and allows the binding even of low affinity antibodies. In contrast, rheumatoid factors in the solid phase capture assay specifically bind human and baboon IgG, but surprisingly do not bind rabbit, horse, marmoset, bovine, macaque, chimpanzee, gorilla, owl monkey, and orangutan IgG. This finding was further confirmed by the competitive assay where only aggregated human and baboon IgG inhibited the binding of radiolabelled aggregated human IgG. It is likely that binding of aggregated IgG from the soluble phase depends on higher affinity antibody. Thus the capture assay provides an excellent opportunity to determine more precisely the fine specificity of IgM rheumatoid factors in serum from patients with rheumatoid arthritis.

Using a discriminant analysis of the results obtained from the earliest available serum sample from these patients, all seen within one year of onset of a polyarthritis which satisfied, as a minimum, the criteria for 'possible' rheumatoid arthritis, we were able to discriminate completely between the patients who went on to develop mild erosive changes or none at all and those who developed moderate or severe erosions.

To achieve this $100 \%$ discrimination a combination of antiglobulin tests was used. The panel was selected by the discriminant analysis programme and ranked in importance. When the discrimination obtained with different isotypes was compared IgM gave the greatest discrimination followed by IgA and IgG. The most discriminating individual factors are IgM antiglobulins with specificities for IgG from species closely related to man but not to human IgG itself. This may suggest that the antiglobulins bind to an altered human IgG, possibly one which has undergone mutation or has altered glycosylation, ${ }^{12}$ and that the altered form is more like, say, gorilla IgG than unaltered human IgG. It may also be argued, however, that the specificities detected in the serum are those which are non-complexed, and that the specifically antihuman IgG has been complexed by the large pool of human IgG in the serum and is thus not available for test in the serum samples. There is evidence to suggest that rheumatoid factors released from cells have higher affinities than those found in the serum, implying local complexing of the rheumatoid factor. ${ }^{13}$ The finding that rheumatoid factors freshly released from synovial cells are able to bind IgG3, in contrast with serum rheumatoid factor, indicates that serum may contain a more limited range of specificities than those in synovial cells. ${ }^{14}$ When the solid phase capture assay was used, however, only mildly aggregated human and baboon IgG were bound by the IgM rheumatoid factor, which suggests that the IgM rheumatoid factor has a higher affinity for human and baboon IgG; on an evolutionary basis gorilla and chimpanzee are closer to human as they are in the same superfamily,
Table 4 Evolutionary interrelationship between species of IgG used

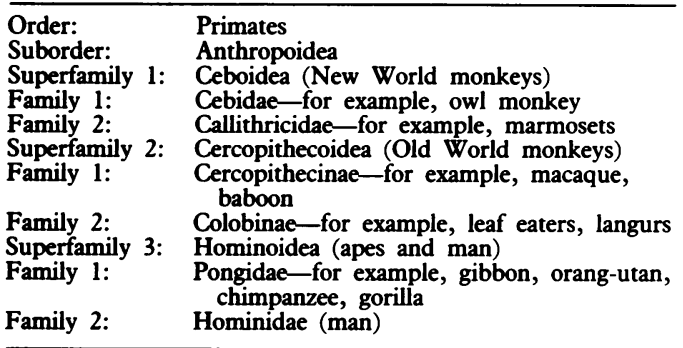

whereas baboon is a member of a different superfamily (table 4). Surprisingly, the levels of capture binding of aggregated human and baboon IgG did not have a higher association with erosions than did the $\operatorname{IgM}$ antiglobulins as determined by the solid phase assay to species closely related to man. If the specificity of the already complexed rheumatoid factor were determined, however, all the reactivity might be to human IgG.

Staphylococcal protein A binds to IgG in a similar fashion to rheumatoid factor. It is interesting that work on IgG from a limited range of species has shown a similar ranking order for binding protein $\mathrm{A}$ to that which we have found for rheumatoid factor, ${ }^{15}$ lending support to the hypothesis that the rheumatoid factor binding site is the same as that for protein A. ${ }^{16}$

One of the aims of a long term study such as the Middlesex prospective study is to set up hypotheses for the earlier patients and then to test them on a later group of patients. The ability to predict in the second group of 40 patients using the discriminant function derived from the first $\mathbf{4 8}$ is disappointing, being only $65 \%$ accurate; the discrimination on the first group from which the panel was derived being $100 \%$. This may reflect either the fact that a larger initial group is required for the development of satisfactory predictive data, or perhaps, more probably, that the patients enrolled had several different and as yet unrecognised subtypes of disease which are differently represented in the two groups. Possibly, fitting the data to be $100 \%$ perfect makes the equation too restrictive to one set of patients. Setting the limits at, say, $95 \%$ may result in a more representative function, which could be more satisfactorily applied to another group of patients.

It was striking that using Friedman's analysis highly significant trends were obtained, indicating that those patients ranking highest for one species of IgG would also be the same patients with the highest activity for the whole panel. This rules out the hypothesis that certain patients might bind strongly to some species of IgG while binding weakly to others. Thus it seems that the different courses of disease are not related to the pattern of antiglobulin reactivity detected in the serum, but that the most significant risk factor for development of erosiveness is the amount of antiglobulin formed.

1 Pike R M, Schulze M L. Species specificity of globulins in reaction with rheumatoid arthritis serum. 7 Immunol reaction with $1963 ; 91$ : $740-7$. 
2 Torrigiani G, Roitt I M. Antiglobulin factors in sera from patients with rheumatoid arthritis and normal subjects: quantitative estimation in different immunoglobulin classes. Ann Rheum Dis 1967; 26: 334-41.

3 Lospalluto J, Ziff M. Chromatographic studies of the theumatoid factor. $\mathcal{F}$ Exp Med 1959; 110: 169-86.

4 Fudenberg $\mathrm{H} \mathrm{H}$. Complete immunology: Science or septophrenia? Clin Exp Immunol 1967; 2: 1-18.

5 Ilter $\mathrm{O} \mathrm{D}$, Turner $M W$. Determination of IgG antiglobulins in rheumatoid disease using insolubilised human IgG. Clin in rheumatoid disease using inso

6 Normansell D E, Stanworth D R. Interactions between rheumatoid factor and native IgG-globulins studied in the ultracentrifuge. Immunology 1968; 15: 549-60.

7 Fleming A, Crown J M, Corbett M. Prognostic value of early features in rheumatoid disease. $\mathrm{Br}$ Med $\mathrm{F} \mathrm{1976;} \mathrm{i:} \mathrm{1243-5.}$

8 Lawrence J S. The epidemiology of chronic rheumatism. Vol II. Oxford. Blackwell Scientific, 1963.

9 Diem . K, Seldrup J. In: Lentner C, ed. Introduction to scientific tables. Vol 2.8th ed. Basle: Geigy, 1982.

10 Meddis R. Statistical handbook for non-statisticians. London: McGraw-Hill, 1975.
11 Klecka W R. Discriminant analysis. In: Nie $\mathrm{N} \mathrm{H}$, Hull $\mathrm{C} \mathrm{H}$, Jenkins J G, Steinbrenner $\mathrm{K}$, Bent $\mathrm{D} \mathbf{H}$, eds. SPSS statistical package for the social sciences. 2nd ed. New York: McGraw-Hill, 1975.

12 Parekh R B, Dwek R A, Sutton B J, et al. Association of rheumatoid arthritis and primary osteoarthritis with changes in the glycosylation pattern of total serum IgG. Nature 1985; 316: 452-7.

13 Robbins D L, Moore T L, Carson D A, Vaughan J H. Relative reactivities of rheumatoid factors in serum and cells. Arthritis Rheum 1978; 21: 820-6.

14 Robbins D L, Skilling J, Benisek W F, Wistar R Jr. Estimation of the relative avidity of $19 \mathrm{~s}$ IgM rheumatoid factor secreted by rheumatoid synovial cells for human IgG factor secreted by rheumatoid synovial cells

15 Kronvall G, Ulysses S S, Fusted J, Williams R C. Phylogenetic insight into evolution of mammalian $\mathrm{Fc}_{\mathrm{c}}$ fragment of gamma G globulin using staphylococcal protein A. F Immunol 1970; 104: 140-7.

16 Nardella F A, Tellar D C, Barber W F, Mannik M. IgG rheumatoid factors and staphylococcal protein $A$ bind to a common molecular site on IgG. F Exp Med 1985; 162: 1811-24. 